DOI: https://doi.org/10.47405/mjssh.v6i4.728

\begin{tabular}{|c|c|}
\hline & Malaysian Journal of Social Sciences and Humanities (MJSSH) \\
\hline Malaysian Journal of & Volume 6, Issue 4, April 2021 \\
\hline (mJ-sSH) & e-ISSN : 2504-8562 \\
\hline & $\begin{array}{l}\text { Journal home page: } \\
\text { www.msocialsciences.com }\end{array}$ \\
\hline
\end{tabular}

\title{
Exploring the Needs for the Development of Organic Reaction Teaching Model: Experts' Collective Opinion
}

\author{
Abdulmalik Sabitu1 ${ }^{\text {, Othman Talib }}{ }^{2}$, Norizah Abdul Rahman ${ }^{3}$, Nurzatulshima Kamaruddin ${ }^{2}$ \\ ${ }_{1}^{1}$ Federal University Dustin-Ma, Katsina State, 821, Nigeria \\ ${ }^{2}$ Faculty of Educational Studies, Universiti Putra Malaysia, 43400, Serdang, Malaysia \\ ${ }^{3}$ Faculty of Science, Universiti Putra Malaysia, 43400, Serdang, Malaysia \\ Correspondence: Othman Talib (otalib@upm.edu.my)
}

\begin{abstract}
This article reported the findings of a study carried out to investigate the needs for developing an organic reaction mechanism teaching model. Qualitative data was obtained through a semi-structured interview among five chemistry subject matter experts to explore their opinion on the issues centred on the teaching and learning of organic reaction mechanisms. The interviews were interpreted and analysed using thematic analysis. Five themes comprising of many codes and quotations were identified. The analysis of the findings shows that organic reaction mechanisms are one of the most significant and central concepts in science. However, students are faced with challenges in learning the concepts. Thus, the need for an alternative model of teaching the concept of organic reaction mechanisms.
\end{abstract}

Keywords: instructional model, organic reaction mechanism, experts' opinion

\section{Introduction}

Organic chemistry is not a new discipline to be introduced. Organic chemistry is defined as the study of carbon and its derivatives in the different states of matter (Anzovino \& Bretz, 2016). The concept covers most of the classes of the organic compound including hydrocarbons, benzene compounds, and their derivatives, haloalkane, carbonyl compounds, amines, carboxylic acids, amino acids, and polymer compounds and the mechanisms of their reactions(Azraai, Ibrahim, \& Talib, 2015). Many topics in organic chemistry including functional groups, electrophiles, nucleophiles, and synthesis were considered central in various scientific fields of economic advancements, such as petrochemicals, textile sciences, food, sciences, and medicinal sciences (Bodé, Deng, \& Flynn, 2019; Cooper, Stowe, Crandell, \& Klymkowsky, 2019). However, the concept has been difficult to the students and this has been attributed to the lack of explicit teaching models and poor knowledge of the basic organic chemistry concepts (Bongers, Northoff, \& Flynn, 2019; Gilbert, 2005). Arrow pushing technique is commonly used in conventional teaching of organic reaction. The technique involve the use of curved arrows to demonstrate electrons' movement (Tsaparlis \& Sevian, 2013). Figure 1 is an example of curved arrows used to teach organic reactions. 
Fig. 1: The example of a curved arrow in organic mechanism reaction
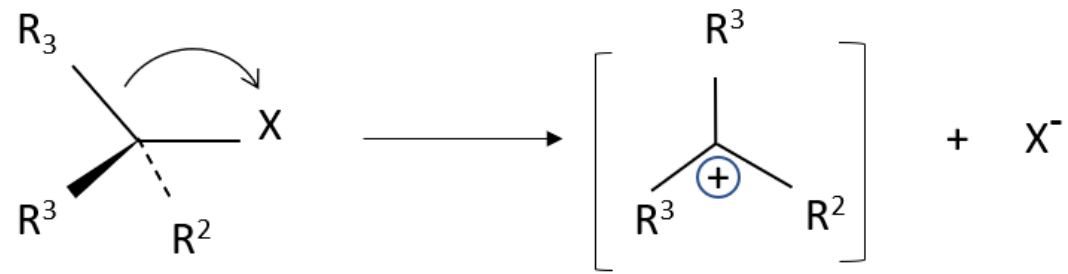

Although researchers have used different names to describe the technique, arrow-pushing techniques and electron-pushing formalism have been used interchangeably in the literature., Bhattacharyya (2013) defined electron-pushing formalism as the technique used for symbolizing the movement of electrons to illustrate organic reactions. This shows that both electron-pushing formalisms and electron-pushing techniques were an explanatory and a predictive method for mechanistic thinking about what happen during reaction mechanisms. Wilson and Varma-Nelson (2018) reported that electron-pushing formalisms were rooted in a paper written by Kermack and Robinson (1922), that described the electrons move from a high electron density to a low-density area within the covalent bond.

The arrow pushing technique was described by Levy (2008) as the use of arrow (s) to show the movement of electrons using a curved arrow from a region of high electron density to a region of low electron density during the formation and breakup of a covalent bonds. Nonetheless, using a curved arrow to illustrate electron movement increases the cognitive load of the students (Talib et al., 2012). This contributed to rote learning of the reaction mechanisms as a single indivisible entity by the students, despite teachers' attempts to help them conceptualize the mechanisms as a procedural process involving a paradigmatic sequence of steps. Besides, the number errors made by students in organic reaction mechanisms were as a result of memorizing the concepts as unanalysed pieces of information (Bodé, Deng, \& Flynn, 2019; Carle, Visser, \& Flynn, 2018 \& Grossman, 2003). Also, abstract and complexity of the concepts (Bhattacharyya, 2019); lack of working memory space (Merrienboer et al., 2010); overuse of direct instruction (Achimugu, 2018); communication language (Flynn \& Featherstone, 2017), and lack of students' motivation (Mohtar et al., 2019) were the contributing factors to learning difficulties of organic reaction mechanisms.

An instructional model is the broadest level of teaching practice that gives instruction a philosophical orientation. Usually used to pick and organize teaching tasks, techniques, skills, and students' interactions with a specific focus on instruction (Richey \& Klein, 2005). In this context, a model is defined as a group of organized instructional activities that would be used by chemistry teachers in designing instructional modules to avoid common errors in drawing organic reaction mechanisms. The commonly used instruction model for teaching chemistry is the chemical representation model suggested by Johnstone (1993). This model proposed that the concepts of chemistry could be represented and expressed on the basis of the three levels of description also known as the chemical triangle, which represent the concepts of chemistry as macro, micro, and symbolic levels to define entities and processes which are visible and identifiable in our environment.

Fig. 2: Chemical Representation Model (Johnstone, 1990)

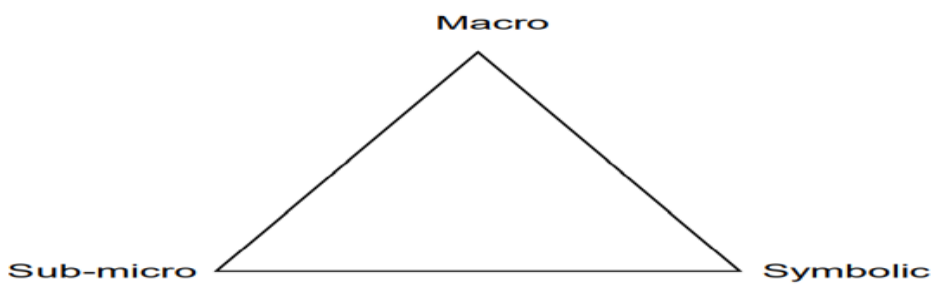

This representation served as a point of reference for various studies on chemistry education, and to simplify the work of science educators worldwide (Cheng \& Gilbert, 2017; Gilbert \& Treagust, 2009; 
Goyena, 2019; Sevian \& Talanquer, 2014; Taber, 2013b, 2013a; Talanquer, 2011; Talib et al., 2012; Treagust, Chittleborough, \& Mamiala, 2003). Yet, Johnstone's chemical triangle has been undergoing a series of adoption and adaption by many scholars from which different interpretations of the chemical triangle have been generated. Yet, chemist continues to ask the question; in what way can the macrolevel be considered a "representation" of things which are measurable and tangible? On this basis, more debate is required on the interpretation and reflection of these three main components for a deeper understanding of the topic of chemistry. In the preparation of chemistry instruction, part of this adaptation of the original chemical triangle required chemistry teachers to concentrate more extensively on alternative models, especially in the teaching of organic chemistry involving invisible processes that must be made explicit. This is because the reinterpretation of the model generated a lot of confusion and misunderstanding (Talanquer, 2011).

This representation served as a point of reference for various studies on chemistry education, and to simplify the work of science educators worldwide (Cheng \& Gilbert, 2017; Gilbert \& Treagust, 2009; Goyena, 2019; Sevian \& Talanquer, 2014; Taber, 2013b, 2013a; Talanquer, 2011; Talib et al., 2012; Treagust, Chittleborough, \& Mamiala, 2003). Although, Johnstone's chemical triangle has been undergoing a series of adoption and adaption by many scholars from which different interpretations of the chemical triangle have been generated. Yet, chemist continues to ask the question; in what way can the macro-level be considered a "representation" of things which are measurable and tangible? On this basis, more debate is required on the interpretation and reflection of these three main components for a deeper understanding of the topic of chemistry. In the preparation of chemistry instruction, part of this adaptation of the original chemical triangle required chemistry teachers to concentrate more extensively on alternative models, especially in the teaching of organic chemistry involving invisible processes that must be made explicit. This is because the reinterpretation of the model generated a lot of confusion and misunderstanding (Talanquer, 2011).

An instructional model can be developed either by studying specific theories, models, literature and experts opinions or adopted from existing models to suit the needs of the study (Richey \& Klein, 2007). Model development involved several phases and stages. The process also involved engaging with specific existing models of instructional design that suit the model objective. Novak model, Repair learning theory and threshold concept theories were considered appropriate and adopted for this study. Based on the existing model and theories, the model development in this study can be carried out in three phases: need analysis, design and development phase and model validation. This article focuses on the first phase; the need analysis of the model development to find out if there is need for the organic reaction teaching model to be develop. Thus, only the result of the analysis phase will be reported in this study. The main objective of the study is to identify the needs for developing the organic reaction teaching model based on the experts' collective opinion. Therefore, this question was raised to guide the study: Based on experts' opinion, to what extent developing an instruction model for teaching organic reaction mechanisms is necessary?

\section{Method}

A qualitative research method using an exploratory design were used in this study. The approach was used to figure out if the teaching model of organic reaction mechanisms is necessary for improving the understanding of organic chemistry by students. The experts were consulted to share their perspectives on issues and suggest strategies for improving the teaching of ORM. The participants chosen to partake in phenomenological research must have a shared experience of such a phenomenon (Englander, 2016). Therefore, 5 seasoned lecturers who are specialists and professionals in chemistry education with more than 10 years of shared experience have been selected purposefully. This is in accordance with Creswell (2014), which suggested participants ranging from 5 to 25 as adequate for qualitative research and Morse (2000) suggested that in the phenomenological study, fewer participants ranged from 6 to 10 were appropriate. A 100RM gift card was received by each of the experts as a compensation for completing the interview. The participants were referred to using pseudonyms in this report as experts. The researcher developed an interview protocol composed of seven semi-structured interview questions and dully checked by three experts before the interview session. Earlier on, the 
respondents were introduced and asked to fill in the interview's personal information and consent documents. The interviews were recorded and transcribed by the interviewer for data processing and all the information obtained from the interviews were analysed using Atlast.ti8 software into themes, subthemes, and codes.

\section{Results and Discussion}

The questions asked during the interview session are meant to answer the research question as follows: Based on experts' opinion, to what extent developing a science-based instruction model for teaching organic reaction mechanisms is necessary? Five main themes that emerged from the experts' interviews were the significance of organic reaction mechanisms, students' common errors in ORM, difficulties in teaching and learning of ORM, teaching strategy, and ways of improving ORM instruction.

\section{Theme One: Significance of Organic Reaction Mechanisms}

The Organic reaction mechanism (ORM) is one of the important concepts in the organic chemistry curriculum. ORM is the key concept in organic synthesis that described the step by step of how the reactants are converted to products. The reaction mechanism has been defined as simply the detailed, step-by-step description of the pathway by which reactants are converted to product. The concept has three main aspects to be covered for a better understanding of organic reactions which are: (i) formation and breaking of bonds (ii) Movement of electrons (iii) factors governing reactions of different functional groups. The teaching of organic reaction mechanisms starts at matriculation to undergraduate and graduate-level of the university chemistry and other science-related programmes like agriculture, food science, medicine, and pharmacy. The concept is spiral in the organic chemistry curriculum comprising of language symbolisms, mechanistic reasoning, and visual representation of the reaction mechanisms involving organic compounds. From the interview session, two codes that arose under the theme of the Significance of Organic Reaction Mechanisms were Fundamental Concepts and Application. The emerging themes and codes are outlined using schematic diagrams in Figure 3.

Fig. 3: Significance of ORM

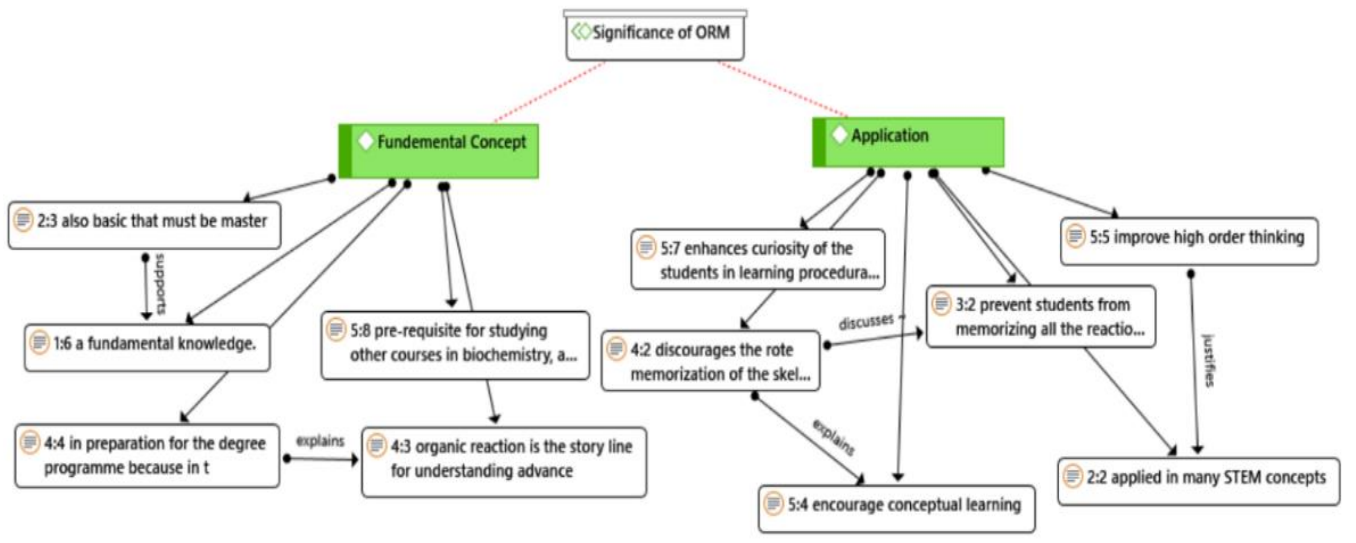

All five experts agreed that organic reaction mechanisms are the fundamental concepts required to master or learn more advanced organic reactions. Since ORM is concerned with the step-by-step processes at the bond formation and breaking during the reaction, ORM is a crucial concept to be understood to have a conceptual understanding regarding the movement of electrons across reacting molecules. Quoting expert 2's words, "students can apply the concepts of organic reaction mechanisms in other advanced Organic chemistry concepts". Expert 3 supported this statement by 
stating the examples of the relevant concepts that also require an understanding of the organic reaction mechanisms, such as organic synthesis and metabolisms in biochemistry.

The content in the organic chemistry curriculum reveals that the concept of organic reaction mechanisms is repeated in future courses at higher levels of university science-related programmes in topics such as food classes, nutrition, soil chemistry in food science and agriculture, synthesis of enzymes in biochemistry, and drug synthesis in pharmacy. Expert 1 said, "students would not be able to explicitly explain the processes involved in the synthesis of complex compounds if they failed to comprehend the organic reaction mechanisms concepts". This statement was supported by expert 4 which later added; that because students were unable to understand organic reaction mechanisms, they faced difficulties in understanding other advanced courses in agriculture, biological sciences, biochemistry, chemistry, and health and pharmaceutical sciences. Furthermore, organic reaction mechanisms have applied to the advancement of students' learning. Expert 5 noted that the procedural nature of ORM improve high order skills, curiosity, and encourage understanding of other concepts in the STEM-related disciplines. This was further emphasised by expert 4 that understanding organic reaction mechanisms discourage rote memorization among students.

\section{Theme Two: Challenges in ORM Instruction}

There are many challenges encountered by the students in the learning of organic reactions. The five experts interviewed shared several viewpoints on the difficulties faced by students during the process of the study. There are six codes listed under this theme: abstract nature, lack of mechanistic reasoning skills, difficult terms, misconceptions, heavy content, and students' attitudes. The emerging theme and codes were outlined using schematic diagrams in Figure 4

Fig. 4. Challenges in ORM Instruction

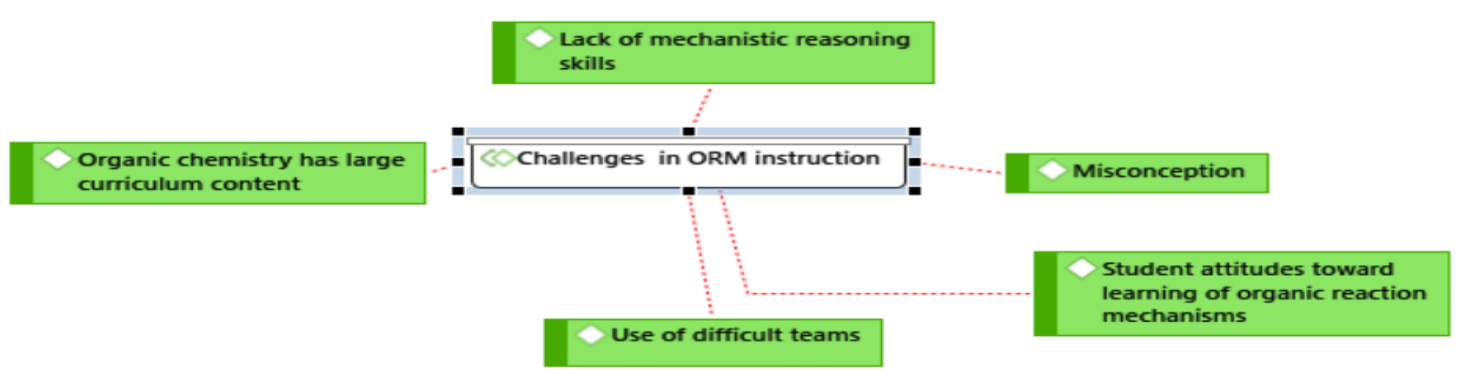

From the results, it was found that there are many associated quotations shared between 'difficult terms' and the 'abstract nature of the topic' codes. As reported from previous studies many students regarded chemistry as a difficult, complex, and abstract subject requiring unique intellectual ability and extra effort to be understood (Gabel, 1999b; Johnstone, 1991; Nakhleh, 1992). Findings from the interviews indicated that the sources of students' difficulties in learning organic reaction mechanisms originated from the inaccessibility of the concept by the nature of science itself; the strategies that we have traditionally taught the concepts and the learning strategies used by students are at conflict with one or both of the above. For example, Expert 3 said, "unlike other disciplines, learning chemistry depends on making sense of the invisible and untouchable". As a result, need to be guided on how to visualize the microscopic processes during reaction mechanisms. However, expert 1 said, "students experienced difficulties in understanding various terminologies necessary for learning organic reaction mechanisms". This statement was supported by the other two experts as they reported that "terms such as lone pairs, an electron source, heterolytic and homolytic cleavage, nucleophiles, electrophiles, and electron sink are difficult to comprehend by students". According to Expert 2, students failed to understand the terms because the terminologies are presented to them as jargon.

Lack of mechanistic reasoning skills was also reported as a hindrance to students' understanding of organic reaction mechanisms. According to all five experts, most students were unable to apply the knowledge they learned to draw reasonable organic reaction mechanisms. Most of the time, students memorized by rote the mechanisms step in the textbooks and teachers' notes. Hence, failed to provide 
an alternative explanation based on their understanding. For example, expert 3 illustrated students' answers that: "...... students often confused in recognizing and applying nucleophilic and electrophilic principles in given reaction mechanisms". He added that students also have difficulties in explaining the differences in the product formed when the reaction is conducted in an acidic or basic medium. These challenges resulted in the high frequency of misconceptions in learning organic reaction mechanisms among the students. Students' attitudes also contributed to the difficulties in teaching and learning Organic chemistry. For example, expert 4 lamented that most of the students believed reaction mechanisms can only be learned through rote memorization. Their participation was low and hardly ask a question during the lesson. Expert 5 said, "teachers would assume that students understanding the lesson taught because not many of them ask questions". However, expert 4 said, "students do not ask questions because they do not understand the concepts taught by experts. Expert 2 also added that the lack of questions from the students is mostly due to a lack of knowledge of the basic concepts. Furthermore, all five experts agreed that the mindset of the students that chemistry concepts cannot be understood influenced their learning style and make them rely solely on rote memorization. They added that because of the large contents and Spiral nature of organic reactions, it is hard to memorise all the reaction mechanisms. Thus, students often get confused thereby making a lot of errors in solving organic reaction mechanisms tasks.

All five experts agreed that active classroom participation has the potential to reinforce students' conceptual understanding. However, in the matriculation programme, experts have a time constraint that eluded them to deliver different activities in the classroom. Experts also need to rush at certain topics to ensure that all topics in the curriculum specification are covered in time. Expert 1 pointed out: "Matriculation programme has a duration of only one year and organic chemistry content is heavily loaded". She added that "I and my colleagues have no option than to rush our lessons before it exceeded the time allocated to complete the syllabus". Expert 4 and Expert 1 also agreed that using media such as videos will help to visualize the movement of electrons during mechanisms. However, due to time constraints, most experts were unable to download videos and applications for teaching the students. They, however, advise them to download by themselves.

\section{Theme Three: Students' Common Errors in ORM}

Chemistry experts are warned about common pitfalls and misconceptions that cause difficulties for students in learning organic reaction mechanisms (Holman, 2003). Hence, experts are expected to pay attention to the students' common errors, as failure to observe their strictures has caused many examination points to be lost over the years. Findings from the interview sessions revealed two main codes under the theme of students' common errors as follows: Wrong use of arrows and poor knowledge of basic concepts. The emerging themes and codes were depicted using schematic diagrams in Figure 5.

Fig. 5. Students' Common Errors in ORM

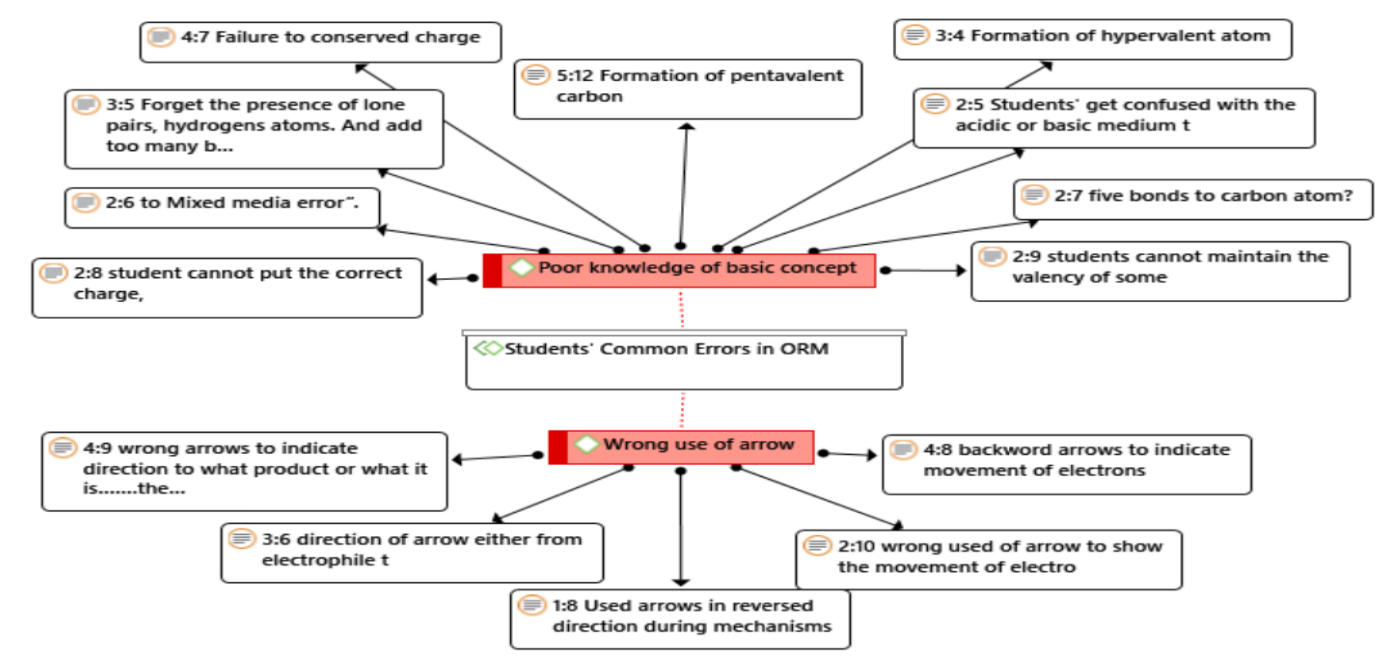


From the analysis, it can be found that many associated quotations were identified from the result of the experts' interviews. Describing students' common errors, Expert 1 remarked that 'students' failure to keep track of electrons makes them not to use enough arrows during mechanisms". This is a common error where arrows indicate a crucial step in the mechanisms is missing thereby making them put more electrons in one atom and incomplete octet in another atom. Another arrow pushing related error commonly made by students is reversing arrows, in this error, students use backward arrow which signifies moving atom instead of the electron. These were reported by expert 4 and Expert 2 "that some students draw the arrow during mechanisms indicating electron was sourced from an atom instead of bonds or lone pairs".

On the theme of the poor knowledge of basic concepts, three related quotations were identified that described common errors made by students which include hypervalent, mixed media errors, and failure to conserve charges. Quoting expert 5, he lamented that "students' poor knowledge of an overarching principle of organic chemistry that carbon has eight electrons in its valence shell when in stable organic molecules called the octet rule has led to forming hypervalent atoms". The rule is also obeyed by many other most common elements in organic molecules, such as chlorine, nitrogen, and oxygen. Expert 2 added, "that many other students tend to get confused with the acidic or basic medium thereby predicting wrong product of the reaction that leads to mixed media error". This occurred when strong acids and bases co-exist simultaneously in the same medium. This resulted in a rapid proton transfer reaction before anything happen in the solution. Another golden rule in reaction mechanisms is that overall charge in all mechanism's steps must be conserved. However, according to Expert 4, because of students' poor knowledge of ionization and chemical bonding, errors are made in the conservation of charges during mechanisms. He stated that failure to conserve charges leads to further errors like the formation of hypervalent atoms. Thus, all the five experts agreed that errors made by students initially emanated from the abstract nature of chemistry subject in general due to poor understanding of basic concepts such as chemical bonding, Lewis acid-base theory, and ionization. However, the situation was worsened due to increasing difficulties as new vocabularies and arrow pushing formalisms were introduced.

\section{Theme Four: Teaching Strategies}

This theme consists of two major codes: arrow pushing technique and the conventional lecture method. The emerging themes and codes are illustrated using schematic diagrams in Figure 6.

Fig. 3: Teaching Strategies

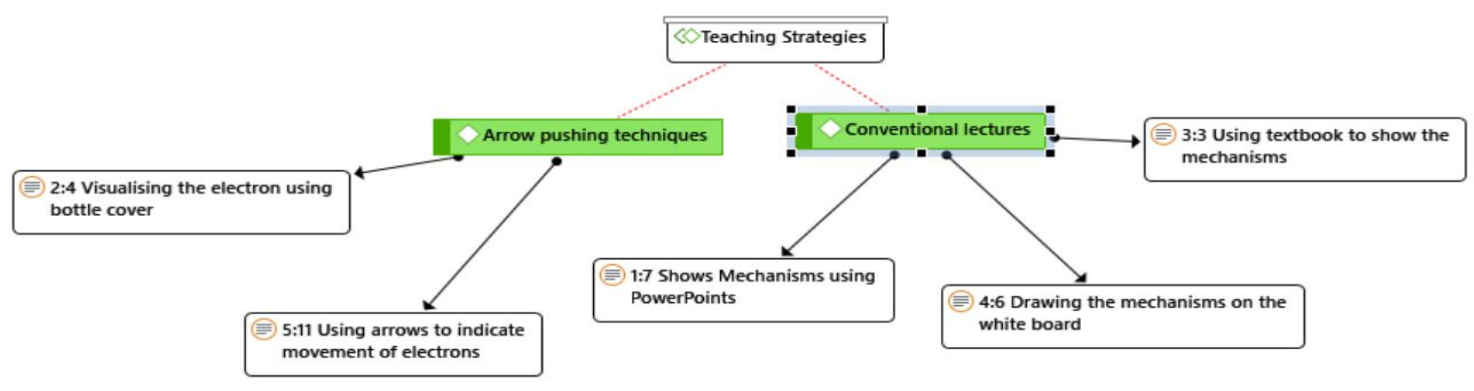

Both experts concluded that in their experiences with students, they used the conventional lecture method, arrow pushing technique, and visualization techniques to teach organic reaction mechanisms. As Expert 3 responded, "I prefers to draw the mechanisms on the whiteboard traditionally and asks students to draw them together with me". Expert 1 stated that "she uses a PowerPoint presentation to show the mechanistic process". She agreed that it was quite challenging to show the movement of the electron using such a strategy. On the other hand, Expert 2 preferred to refer to mechanisms in the textbook due to the time constraint that eluded her to prepare other teaching materials for her students. For Lecture 5, she always used the bottle cover of a different colour to familiarise her with mechanisms and enhances students' understanding, and she usually used red coloured bottle cover for electrophiles and white bottle cover for nucleophiles to her students during her lessons. Her justification for this 
strategy is to ensure that students understand and still remember the role of electrophile and nucleophiles concepts as the threshold for understanding reaction mechanisms. Expert 3 also points out that the repetition of the information is essential to help to retain the information in their long-term memory. Expert 3 later added, "Difficult terms in organic reaction mechanisms need to be memorized, there is no other way for the students to familiarize themselves with the terms. We, as experts, ought to play a part in helping them memorize these terminologies".

All the five experts shared the same perspectives on the use of arrow pushing techniques which involve the use of arrows to indicate the movement of electrons. Expert 2, "stated that arrow pushing is used to show the source and the destination of electrons during mechanisms". Expert 4 added that visual representations are needed to assist in visualizing the microscopic process during mechanisms as claimed to be used by expert 5 . However, experts hardly representation techniques to explicitly show the process taking place during reaction because it is time-consuming. Furthermore, the use of arrow pushing formalisms is advantageous to help to understand language symbolisms and mechanistic reasoning. Through these learning activities, students will be able to apply the concepts taught in understanding advanced organic reactions and other essential mechanisms such as photosynthesis, respiration, and synthesis of enzymes in biological science.

\section{Theme Five: Improving ORM Instruction}

From the interview session, all the five experts voiced out their desired improvements in teaching organic reaction mechanisms which are summarised into three categories as teaching strategy, content knowledge, and students' attitude. Findings show that students rarely participated during organic reaction mechanisms lessons except in classroom assignments. The expert 2 commented that the "attitude of students should be encouraged towards participation in the classroom through cooperative and collaborative approaches such as pairs and groups learning". Active participation can help the experts to measure two variables: students' interest and performance. Meanwhile, group activities will encourage classroom interaction. Expert 3 added that "Experts also have to play an important role by engaging students in group learning tasks". Furthermore, the use of visual aids in demonstrating bond cleavage also improves students' participation. This statement was supported by expert 4 where he stressed that "the use of visual aids in teaching reaction mechanisms improve students' curiosity and attention". The emerged sub-theme and codes are summarised using schematic diagrams in Figure 7.

Fig. 4: Desired Improvement

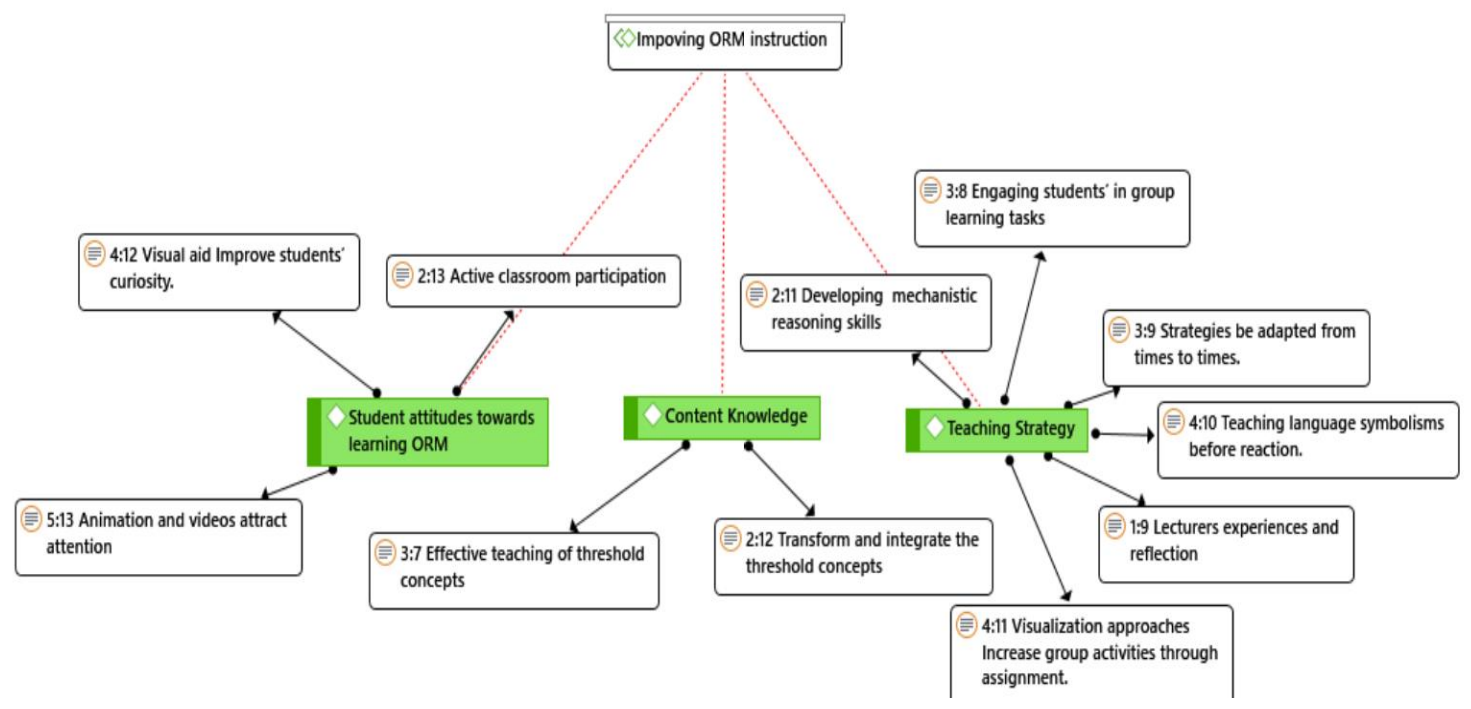

Under the teaching strategy sub-theme, all five lectures agreed that alternative strategies in teaching ORM need to be developed for the explicit presentation of the microscopic process in the reaction. This would encourage the active participation of the students. For example, expert 1 said, " ... I believe 
using visualization in form of animation and videos could help to visualize the processes ". This is further expert 4 and expert 2, who opined that most of the students can understand organic reaction mechanisms easier through visualization. From the viewpoint of these experts, ORM is significant for students to grasp the fundamental principles of advanced organic reaction and to extend the knowledge around chemistry subject. However, the main difficulty faced by students is their inability to relate the abstract processes in reaction mechanisms with other chemistry concepts. Therefore, it is essential to transform and integrate the threshold concepts such as nucleophiles, electrophiles, chemical bonding, and atomic structure that are prerequisites for a conceptual understanding of organic reaction mechanisms. This is supported by expert 3 who said that "due to the spiral nature of the organic reaction mechanisms, it is important to bound all its crosscutting concepts for effective learning".

Furthermore, expert 5 lamented that "teaching the symbolic language before the reaction will help students in understanding the arrow pushing formalisms". This statement was reiterated by expert 2 and 3 who stated that "unless students' mechanistic reasoning skills are developed, they would continue to memorize mechanisms by rote". Similarly, expert 1 noted that "there is a need for experts to use their experiences by reflection to share with their students' common errors identified in their previous classes". Based on the experts' perspectives, the large volume of the organic chemistry curriculum prevents teachers to use individualized teaching approaches, that utilise chemical triangle (Johnstone, 1990) as a framework to explain the hidden features of organic reaction mechanisms. This demonstrates a further need for alternate instructional modules to develop for successful ORM teaching. There is also a need for a philosophic connection of the constructs such as language symbolism, mechanistic reasoning, and visual representation, and the transformation of threshold concepts to enhance the teaching and learning of ORM.

\section{Conclusion}

Generally, the findings of the need analysis have shown that organic reaction mechanisms consist of complicated and dynamic principles that are essential and need to be clarified through a robust model developed with mechanistic reasoning, language symbolisms and visual representation for a better understanding of advanced organic reactions. The development of the organic reaction teaching model is based on pre-requisite concepts such as electrophiles and nucleophiles. Therefore, it is essential to transform and integrate the threshold concepts such as nucleophiles, electrophiles, chemical bonding, and atomic structure that are prerequisites for a conceptual understanding of organic reaction mechanisms. Organizing basic concepts that are transformative, integrative, and connected up with concepts of organic reaction mechanisms will make learning meaningful. It is therefore important to develop organic reaction mechanisms teaching model, particularly at the pre-university level, in order to develop mechanistic reasoning, visual representation skills and fluent language symbolism of students. Organic reaction mechanisms are basic principles that are important for the analysis of various advanced courses in the University. Experts believe that the learning of organic reaction mechanisms should be encouraged at pre-university level in order to create a solid foundation for the learning of organic chemistry. In order to teach organic reaction mechanisms effectively, the principles of organic reaction mechanisms should be consistently learned with the use of a structured model. This will help students understand and relate what they have learned to the advanced concepts. As there are not many specific models focused solely on organic reaction mechanisms for pre-university students, experts believe that there should be a structured model prepared for chemistry teachers to be used to help students improve their conceptual understanding of organic reaction mechanisms. The findings suggest the need to develop an alternative teaching model or module for teaching organic reaction mechanisms for pre-university students.

\section{References}

Achimugu, L. (2018). Effectiveness of Enriched Demonstration and Lecture Instructional Strategies on Senior Secondary School Students ' Achievement in Chemistry. Journal of Contemporary Educational Research, 2(1), 1-9. https://doi.org/10.26689/jcer.v2i1.246 
Anzovino, M. E., \& Bretz, S. L. (2016). Organic chemistry students' fragmented ideas about the structure and function of nucleophiles and electrophiles: A concept map analysis. Chemistry Education Research and Practice, 17(4), 1019-1029. https://doi.org/10.1039/c6rp00111d

Azraai, O., Ibrahim, D. A., \& Talib, O. (2015). Taksonomi Bloom Asal Taksonomi Bloom Baharu(Old Bloom's Taxonomy New Bloom's Taxonomy). JPBU, 8, 12-21.

Bhattacharyya, G. (2013). From source to sink: Mechanistic reasoning using the electron-pushing formalism. Journal of Chemical Education, 90(10), 1282-1289. https://doi.org/10.1021/ed300765k

Bhattacharyya, G. (2019). Construction by De-construction. Journal of Chemical Education. https://doi.org/10.1021/acs.jchemed.8b00579

Bodé, N. E., Deng, J. M., \& Flynn, A. B. (2019). Getting Past the Rules and to the WHY: Causal Mechanistic Arguments When Judging the Plausibility of Organic Reaction Mechanisms. Journal of Chemical Education, 96(6), 1068-1082. https://doi.org/10.1021/acs.jchemed.8b00719

Bodé, N. E., \& Flynn, A. B. (2016). Strategies of Successful Synthesis Solutions: Mapping, Mechanisms, and More. Journal of Chemical Education, 93(4), 593-604. https://doi.org/10.1021/acs.jchemed.5b00900

Bongers, A., Northoff, G., \& Flynn, A. B. (2019). Working with mental models to learn and visualize a new reaction mechanism. Chemistry Education Research and Practice, 20(3), 554-569. https://doi.org/10.1039/c9rp00060g

Carle, M. S., Visser, R., \& Flynn, and A. B. (2018). Nitrogen-doped Carbon Nanodots for bioimaging and delivery of paclitaxel. Journal of Materials Chemistry B, 6(35). https://doi.org/10.1039/x0xx00000x

Cheng, M. M. W., \& Gilbert, J. K. (2017). Modeling students' visualisation of chemical reaction. International Journal of Science Education, 39(9), 1173-1193. https://doi.org/10.1080/09500693.2017.1319989

Cooper, M. M., Stowe, R. L., Crandell, O. M., \& Klymkowsky, M. W. (2019). Organic Chemistry, Life, the Universe and Everything (OCLUE): A Transformed Organic Chemistry Curriculum. Journal of Chemical Education. https://doi.org/10.1021/acs.jchemed.9b00401

Creswell, J. W. (2014). A concise introduction to mixed methods research. SAGE publications.

Cruz-Ramírez De Arellano, D., \& Towns, M. H. (2014). Students' understanding of alkyl halide reactions in undergraduate organic chemistry. Chemistry Education Research and Practice, 15(4), 501-515. https://doi.org/10.1039/c3rp00089c

Englander, M. (2016). The interview: Data collection in descriptive phenomenological human scientific research. Journal of Phenomenological Psychology, 47(1), 13-35. https://doi.org/10.1163/156916212X632943

Flynn, A. B., \& Featherstone, R. B. (2017). Language of mechanisms: exam analysis reveals students' strengths, strategies, and errors when using the electron-pushing formalism (curved arrows) in new reactions. Chemistry Education Research and Practice, 18(1), 64-77. https://doi.org/10.1039/c6rp00126b

Gabel, D. (1999). Improving Teaching and Learning through Chemistry Education Research: A Look to the Future. Journal of Chemical Education, 76(2-4), 548-554. https://doi.org/10.1021/ed076p548

Gilbert, J. K. (2005). Visualization: A Metacognitive Skill in Science and Science Education. In Visualization in Science Education (pp. 9-27). https://doi.org/10.1007/1-4020-3613-2_2

Gilbert, J. K., \& Treagust, D. (2009). Multiple representations in chemical education (Vol. 4). Dordrecht: Springer.

Goyena, R. (2019). Multiple Representation in Chemical Education. In Journal of Chemical Information and Modeling (Vol. 53). https://doi.org/10.1017/CBO9781107415324.004

Grossman, R. B. (2003). The Art of Writing Reasonable Organic Reaction Mechanisms, 2nd Edition (Grossman, Robert B.). In Journal of Chemical Education (Vol. 80). https://doi.org/10.1021/ed080p1259

Johnstone, A. (1993). Symposium on Evolution in Chemical Education The Development of Chemistry the Teaching. The Forum, 70(9), 701-705.

Johnstone, A. H. (1991). Seldom What They Seem. Journal of Computer Assisted Learning, 7, 75-83.

Levy, D. E. (2008). Arrow-pushing in organic chemistry: an easy approach to understanding reaction 
mechanisms. John Wiley \& Sons.

Merrienboer, J. J. G. Van, Kirschner, P. A., Kester, L., \& Merriënboer, J. J. G. Van. (2010). Taking the Load Off a Learner' s Mind: Instructional Design for Complex Learning Taking the Load Off a Learner' s Mind : Instructional Design for Complex Learning. Educational Psychologist, 38(1), 37-41. https://doi.org/10.1207/S15326985EP3801

Mohtar, L. E., Halim, L., Rahman, N. A., Maat, S. M., Iksan, Z. H., \& Osman, K. (2019). A model of interest in stem careers among secondary school students. Journal of Baltic Science Education. https://doi.org/10.33225/jbse/19.18.404

Morse, J. M. (2000). Determining Sample Size. Qualitative Health Research, 10(1), 3-5. https://doi.org/10.1177/104973200129118183

Nakhleh, M. B. (1992). Why some students don't learn chemistry: Chemical misconceptions. Journal of Chemical Education, 69(3), 191-196. https://doi.org/10.1021/ed069p191

Othman, T., Nawawi, M., Ali, W. Z. W., \& Mahmud, R. (2012). Simple Explicit Animation (SEA) Approach in Teaching Organic Chemistry. Procedia - Social and Behavioral Sciences, 69(Iceepsy), 227-232. https://doi.org/10.1016/j.sbspro.2012.11.403

Richey, R. C., \& Klein, J. D. (2005). Developmental research methods: Creating knowledge from instructional design and development practice. Journal of Computing in Higher Education, 16(2), 23-38. https://doi.org/10.1007/BF02961473

Sevian, H., \& Talanquer, V. (2014). Rethinking chemistry: A learning progression on chemical thinking. Chemistry Education Research and Practice, 15(1), 10-23. https://doi.org/10.1039/c3rp00111c

Taber, K. S. (2013a). Modelling Learners and Learning in Science Education. In Modelling Learners and Learning in Science Education. https://doi.org/10.1007/978-94-007-7648-7

Taber, K. S. (2013b). Revisiting the chemistry triplet: drawing upon the nature of chemical knowledge and the psychology of learning to inform chemistry education. Chemistry Education Research and Practice, 14(2), 156-168.

Talanquer, V. (2011). Macro, submicro, and symbolic: The many faces of the chemistry "triplet." International Journal of Science Education, 33(2), 179-195. https://doi.org/10.1080/09500690903386435

Treagust, D. F., Chittleborough, G., \& Mamiala, T. L. (2003). The role of submicroscopic and symbolic representations in chemical explanations. International Journal of Science Education, 25(11), 1353-1368. https://doi.org/10.1080/0950069032000070306

Tsaparlis, G., \& Sevian, H. (2013). Concepts of matter in science education (Vol. 19). Springer.

Weinrich, M. L., \& Sevian, H. (2017). Capturing students' abstraction while solving organic reaction mechanism problems across a semester. Chemistry Education Research and Practice, 18(1), 169-190. https://doi.org/10.1039/c6rp00120c

Wilson, S. B., \& Varma-Nelson, P. (2018). Characterization of first-semester organic chemistry peerled team learning and cyber peer-led team learning students' use and explanation of electronpushing formalism. Journal of Chemical Education, 96(1), 25-34. 